\title{
An anthropological examination of virtues and character strengths and wellbeing: Imagining a good life in professional training
}

\author{
Christian R. Bellehumeur · Cynthia Bilodeau · Winnie Yeung
}

\begin{abstract}
Since its inception, there has been a rapid growth in the number of studies on Peterson and Seligman's (2004) classification of Positive Psychology's (PP) strengths and virtues, linking them to wellbeing (Brdar \& Kashdan, 2010). However, some authors have criticized this approach (Schwartz \& Sharpe, 2006), arguing that this classification does not integrate a complete understanding of the Aristotelian virtue of practical wisdom. Building on this critique, the article aims to apply the theoretical framework of Gilbert Durand's Anthropological Structures of the Imaginary (ASI) in order to provide a nuanced approach to understanding Positive Psychology's concepts of strengths and virtues. We suggest that this approach will contribute to enhancing the implications of these concepts for the practice of supervision and psychotherapy. In the first section, we explore the notion of virtue from the Positive Psychology perspective and contrast it with the Aristotelian perspective. The comparison of these two perspectives lead to a rationale for proposing Durand's ASI theory for greater understanding of the complexities inherent to the notion of virtues and their associated character strengths and their role in fostering a good life. In the second section, we briefly present an overview of Durand's ASI theory. In the third section, we further demonstrate the links between the two theoretical frameworks (i.e., Durand's ASI and $\mathrm{PP}^{\prime}$ s strengths and virtues), by providing applications of the relevance of ASI to both Peterson and Seligman's (2004) six virtues and 24 character strengths. Lastly, a case conceptualization is presented to articulate the clinical implications of this proposed approach.
\end{abstract}

Keywords: virtues, character strengths, wellbeing, practical wisdom, anthropological structures of the imaginary

\section{Introduction}

When reflecting on our experiences regarding challenging and unpleasant professional encounters, such as challenging psychotherapy sessions, demanding training experiences, or uncomfortable supervisory encounters, it is not uncommon to ask ourselves: How was I doing with this person? In this challenging psychotherapy session, was I fair with this "difficult" client? As a supervisor, was I brave enough to assert myself in a constructive way with what seemed to be a "stubborn" or "anxious" student? Was I kind enough or too kind toward an "unfriendly" or "annoying" colleague? Was I successful in my self-regulation? Was I wise enough?

The above questions are typically associated with one of two circumstances: 1) We question our overuse or underuse of specific traits (e.g., overuse of kindness translating into lack of assertiveness or genuineness); or 2) We question our interpersonal skills and consequently experience lower levels of subjective wellbeing and diminished interpersonal or intrapersonal satisfaction. When in this state of questioning, we may wonder how we can do better next time, or how we can avoid repeating this unpleasant encounter or difficult interaction in the future. In 
other words, we imagine new ways of interacting in a more constructive, efficient and pleasant way when envisioning future challenging encounters.

We experience these moments of self-questioning as part of our daily lives. They manifest themselves in both our personal and professional lives and refer to our ability to envision a "better version" of who we are. In the field of psychology and psychotherapy, it is safe to say that all major schools of thought address the notion of self-improvement, typically with a focus on targeting areas in which we are lacking. The Positive Psychology (PP) movement however, proposes a different approach to self-improvement by identifying character strengths to be nurtured and developed rather than focusing on repairing what is wrong or deficient (Peterson \& Seligman, 2004; Seligman \& Csikszentmihalyi, 2000). The underlying assumption of this approach is that accentuating and exercising personal psychological strengths leads to increased wellbeing and promotes optimal functioning (Peterson \& Seligman, 2004; Seligman \& Csikszentmihalyi, 2000). This new way of conceptualizing virtues and strengths has led to a growing number of empirical studies. With the search engine PsychoInfo, an examination of the number of publications within a three-year period referring to the notions of virtues and strengths ${ }^{1}$ as developed by Peterson and Seligman (2004) since its beginning show the following results: 1) 2004 to 2006: 29 publications, 2007 to 2009: 38 publications, 2010 to 2012: 72 publications, 2013 to 2016: 156 publications. The number of articles examining the notion of virtues and strengths from a Positive Psychology perspective has more than doubled in the past three years. It is worth mentioning that the study of virtues is one of the four pillars of the second wave of Positive Psychology (PP 2.0), along with meaning, resilience and wellbeing (Wong, 2011) which will be discussed further.

Despite this increase in numbers of empirical studies on Peterson and Seligman's (2004) classification of PP's strengths and virtues, Schwartz and Sharpe (2006) have criticized this approach. They argued that PP does not integrate a complete understanding of the Aristotelian virtue of practical wisdom. ${ }^{2}$ Although Peterson and Seligman's (2004) classification does include the virtue of wisdom and knowledge (see Diagram A), and therefore, several strengths (creativity, curiosity, judgment/critical thinking, love of learning, and perspective), according to Schwartz and Sharpe (2006), there are important things worth noting about this list of strengths. Overall, they argue for an integrative and more expansive view of strengths which places (practical) wisdom at the crux of imagination and will. ${ }^{3}$

\footnotetext{
${ }^{1}$ According to a search on PsychInfo with only the expression "Values in Action" (VIA) as a keyword, June $28^{\text {th }} 2017$. ${ }^{2}$ In The Nicomachean Ethics, Aristotle (2000) advances an understanding of ethics known as virtue ethics because of its heavy reliance on the concept of virtue. Derived from the Greek word ethos, ethics refers to the personality and "character" of a person. Aristotle's aim was to describe what constituted excellent character in a person. Aristotle (2000) referred to eudaimonia, which he considered the highest possible good for human beings.

3 "First, we believe that practical wisdom demands all of these strengths. ... Cultivating some of these strengths and neglecting others will lead to an impoverished toolbox - only hammers. Second, we believe that practical wisdom requires other strengths that are not on the Peterson and Seligman list. It requires discernment, perceptiveness, and imagination.... And finally, and most important, the list of intellectual strengths, no matter how extensive, can never completely capture what goes into practical wisdom. For in addition to skill, which is what the intellectual strengths contribute to, practical wisdom requires will. To be wise, it is not enough to know the right thing to do. You also have to want to do it. In the absence of will, the intellectual and emotional skills that make up practical wisdom can be used as instruments of manipulation and abuse" (Schwartz \& Sharpe, 2006, p. 386).
} 
Diagram A. Durand's classification of structures of the imaginary

\begin{tabular}{|c|c|c|c|}
\hline Regimes & Diurnal & $\begin{array}{l}\text { Nocturnal (could be } \\
\text { called Crepuscular) }\end{array}$ & Nocturnal \\
\hline Structures & heroic & $\begin{array}{c}\text { synthetic or } \\
\text { "systemic" }\end{array}$ & mystical \\
\hline Verbal schema & to distinguish & to link & to confound \\
\hline Reflexive gesture & postural & $\begin{array}{l}\text { oscillating, rhythmic } \\
\text { or cyclical }\end{array}$ & digestive or absorbing \\
\hline \multicolumn{4}{|l|}{ Visual representations } \\
\hline $\begin{array}{l}\text { St-Arnaud's (1989) three } \\
\text { axis of group dynamic }\end{array}$ & Axis of productivity & Axis of regulation & Axis of solidarity \\
\hline $\begin{array}{l}\text { Possible encountered } \\
\text { values }\end{array}$ & $\begin{array}{l}\text { Commitment, truth, } \\
\text { boldness, clarity, } \\
\text { justice, equality } \\
\text { wealth, science } \\
\text { authority, autonomy } \\
\text { rational, logic, } \\
\text { territory, freedom, } \\
\text { challenge, to ascend, } \\
\text { demarcation, } \\
\text { ambition, exclusion } \\
\text { slicing, fight, } \\
\text { conquest, purity, } \\
\text { speed, etc. }\end{array}$ & $\begin{array}{l}\text { Coordination, } \\
\text { conciliation, } \\
\text { accommodation, } \\
\text { tolerance, integration, } \\
\text { simultaneity or } \\
\text { unfolding in time } \\
\text { according to either an } \\
\text { eternal return or an } \\
\text { exit from the current } \\
\text { state of the world } \\
\text { (parousia, history, } \\
\text { Point Omega), } \\
\text { mythological mission, } \\
\text { mysteries, etc. }\end{array}$ & $\begin{array}{l}\text { Gentleness, peace, } \\
\text { human warmth, } \\
\text { friendship, solidarity (to } \\
\text { enmesh), sensuality } \\
\text { (touch, taste), grandeur } \\
\text { of the small/weak, what } \\
\text { brings together colors, } \\
\text { resemblance, } \\
\text { inclusiveness, } \\
\text { meditation, reflexion, } \\
\text { inner life, etc. }\end{array}$ \\
\hline
\end{tabular}

Given the complexity of the notion of virtues, one may also wonder how complementary ways of understanding human nature can be taken into account when reflecting on virtues. In this article, we will focus on three possible ways: 1) Peterson and Seligman's (2004) classification on PP's strengths and virtues, 2) Aristotle's perspective of human nature, and 3) Durand's Anthropological Structures of the Imaginary (ASI).

\section{Overview}

The main goal of this article is to apply a theoretical understanding of Durand's ASI for a nuanced understanding of the PP's strengths and virtues in order to enhance further clinical implications. The main question of this analytical essay is the following: How can Durand's ASI framework - proposing three main imaginary mythical categories - inform our understanding of Peterson and Seligman's (2004) classification of virtues and strengths? In order to answer this question, this essay will be divided into three sections.

\footnotetext{
${ }^{4}$ The relevance of these axes to ASI are well explained in Laprée (2013).
} 
In the first section, we will explore the notion of virtue. This will begin with a brief presentation of the Positive Psychology approach, and mostly the notion of Values in Action (VIA), along with Aristotle's Nicomachean Ethics. In an effort to clarify the differences between Positive Psychology's view of strengths and virtues and the Aristotelian perspective, a summary of the critique of Schwartz and Sharpe (2006) will be presented, followed by a rationale to propose Durand's ASI. In the second section, we will summarize Durand's theory of Anthropological Structures of the Imaginary. And thirdly, we will further demonstrate the links between the two theoretical frameworks (i.e., Durand's ASI and PP's strengths and virtues), by providing applications of the relevance of ASI to both Peterson and Seligman's (2004) six virtues and 24 character strengths. This theoretical demonstration will be articulated by presenting a brief clinical case study, the case of Marcella, who presents an ethical challenge within the context of clinical supervision.

\section{Virtues and strengths in Positive Psychology as contrasted by Aristotle's perspective of virtues}

Positive psychology views human beings through a strength and talent lens, rather than a weakness and deficiency lens. While this approach has been endorsed for decades by scholars from humanistic schools of thought and even pastoral counseling, ${ }^{5}$ it is the PP movement that has brought this paradigm shift to self-improvement at the forefront of practice in psychology (Seligman \& Csikszentmihalyi, 2000). In this emerging framework, the notion of virtues ${ }^{6}$ has been a major object of study (Peterson \& Seligman, 2004). From antiquity (Plato, Aristotle), to major religious traditions (monotheism, Hinduism, Buddhism, and so on) to various philosophers

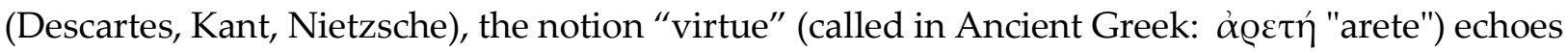
the idea of moral excellence. It opposes the notion of vice, which can be briefly defined as a moral fault or weakness in someone's character or illegal or immoral activities. It is valued as an important principle or foundation of good moral being (Peterson \& Seligman, 2004). Bridging the ancient notion of "virtue" in the modern era of contemporary psychology, Peterson and Seligman (2004) have proposed a classification of six virtues - Wisdom and Knowledge, Courage, Humanity, Justice, Temperance, and Transcendence - with corresponding strengths to assess one's character strength signature (Peterson \& Seligman, 2004). In order to propose this repertoire of virtues and strengths, Peterson and Seligman (2004), along with other colleagues, studied the major world religions and philosophical traditions. After identifying dozens of "candidate strengths," Peterson and Seligman (2004) developed a list of 12 criteria $^{7}$ to help them select the final 24 strengths distributed between six virtue categories (see Appendix 1). The six virtues that emerged (i.e., courage, humanity, justice, etc.) were found to be shared across cultures and throughout time, spanning almost three millennia (Peterson \& Seligman, 2004).

\footnotetext{
${ }^{5}$ These similarities between the humanistic school and Christian spirituality have also been observed (Kaczor, 2015; Zagano \& Gillespie, 2006).

${ }^{6}$ In http://dictionary.cambridge.org/dictionary/english/virtue, the term "virtue" has three main meanings: 1) a good moral quality in a person, or the general quality of being morally good; 2) an advantage or good thing; 3) because of; as a result. This article will focus on the first meaning.

7 Twelve criteria were retained to identify characters strengths: (1) ubiquity (widely recognized across cultures); (2) fulfilling; (3) morally valued; (4) does not diminish others; (5) nonfelicitous opposite (has antonyms); (6) traitlike (shows generality and stability); (7) measurable; (8) distinctiveness; (9) paragons (is strikingly embodied in some individuals); (10) prodigies (is precociously shown by some children or youth); (11) selective absence (is missing altogether in some individuals); (12) institutions (is the deliberate target of societal practices and rituals that try to cultivate it) (Park, Peterson \& Seligman, 2004).
} 
Each of the six identified core virtues has corresponding character strengths. In order to develop this classification, they used various instruments: structured interviews, questionnaires, informant reports, behavioral experiments and observations. Various criteria were used to distinguished character strengths from other related concepts, such as individual talents and abilities (Park, Peterson, \& Seligman, 2004).

These six virtues are considered too abstract to be empirically and systemically studied, and hence, in an attempt to operationalize them, each virtue has a more precise set of character strengths (24 in total for all six virtues). These strengths are considered more practical to foster, and psychometric measures have been developed to measure them, such as the Values in Action (VIA-IS) (Peterson \& Seligman, 2004) and Strengths Use Scale (SUS) (Govindji \& Linley, 2007). Once identified, it is thought that the regular practice of strengths make it possible to attain their related virtue, leading to increases in wellbeing and buffering against mental illness (Peterson \& Seligman, 2004). For example, for temperance, the strengths to be practiced are self-regulation, forgiveness, prudence and humility.

$\mathrm{PP}^{\prime} \mathrm{s}$ understanding of human nature suggests that each personality is composed of a unique makeup of individual strengths and their related virtues, which Peterson and Seligman (2004) refer to as the "character strength signature." However, as Schwartz and Sharpe (2006) have underlined, in this approach, virtues and strengths are treated as logically independent: "that people identify their 'signature' strengths and cultivate them, because more of a strength is better" (p. 377). This view is contrasted by the same authors: "with the Aristotelian view that virtues are interdependent, that happiness (eudaimonia) requires all of the virtues, and that more of a virtue is not always better than less" (p. 377).

According to Kristjánsson (2010), the problem of cultivating signature character strengths is considered one of the main flaws of the approach by Peterson and Seligman:

Positive Psychology asks us to identify our 'signature strengths' ... those items from the virtues and strengths list that we are already best at, and to strengthen those, even at the expense of others (see, e.g., Seligman, 2002, p. 245). Seligman explicitly accepts that people can be virtuous although they do not display all six of the core moral virtues (2002, p. 137); and Peterson and Seligman are 'comfortable saying that someone is of good character if he or she displays but 1 or 2 strengths within a virtue group' (2004, p. 13). There is no attention given to the problem of one virtue colliding with another or to the bigger picture of relevance: how different characteristics fit into a well-rounded life. Rather, individual strengths are treated as logically, empirically, and morally independent from one another ... (p. 306).

In this view, focusing on cultivating signature characteristic strengths rather than emphasizing the unity of character constitutes a significant flaw in Peterson and Seligman's approach (Kristjánsson, 2010). Its focus on developing a limited number of character strengths that are already present may unwittingly produce individuals with certain character strengths but without character and virtue as it is generally understood. For example, some people may be strong in wisdom and knowledge but deficient in other strengths and hence may also be arrogant and disrespectful. In contrast, Fowers (2008) highlights that a virtuous person typically possesses all virtues in various degrees and the disposition to act virtuously requires a sound understanding of how to act rightly at the proper time and place, considering the persons and the context.

For Aristotle (trans. 2000), a moral virtue is defined as a disposition to behave in the right manner when faced with extremes of deficiency and excess (these extremes are called vices). 
Moral virtues are thought to constitute excellence in character and to be primarily learned through practice (and habits) rather than through reasoning and instruction. In summary, a virtue refers to the idea of "an action which is perfectly executed or performed" (Aristotle, trans. 2000). Furthermore, Aristotle (trans. 2000) uses the term phronesis (or prudence) to determine the appropriate or acceptable dose of fear versus intrepidity in a given situation. This is an example of the different ways one can examine any given situation as they attempt to determine the best possible action to carry out. Phronesis relies on the repeated experience of past decisions, which have led to the creation of habits, good or bad. It is these habits which constitute one's acquired character.

According to Aristotle (trans. 2000), everything in nature has a telos, or end goal. The goal of any person is to be virtuous, and, in order to be so, one must act morally. This requires not only that they demonstrate their moral virtues but they must also possess the intellectual virtue of prudence, or practical wisdom (Schwartz \& Sharpe, 2006). This refers to Aristotle's Doctrine of the Mean. ${ }^{8}$ In order to explain his vision of virtue, Aristotle (trans. 2000) proposes a table of virtues that are not intended as a set of exact rules to follow but rather a general guideline. According to him, a virtuous person is one who would demonstrate all the possible virtues, not as distinct qualities, but draw on them differentially in different aspects of their life. In this sense, his table presents only a rough approximation of his conceptualization of virtues and suggests that individuals will vary in how closely their virtues lie to the mean or closer to the extremes (vice) (Aristotle, trans. 2000). In sum, the idea that there are two opposites for every virtue emphasizes the importance of moderation. A virtue is achieved by finding a middle ground, not by aiming for an extreme. However, it can be a struggle to identify exactly where this middle ground lies. Aristotle (trans. 2000) argues that a truly virtuous person, with constant practice, would eventually naturally be inclined to behave appropriately and will have no need for rules.

According to Schwartz and Sharpe (2006, p. 382-383), the Aristotelian perspective differs from the Peterson and Seligman (2004) "strengths and virtues" perspective in three important ways: 1) Strengths and virtues should be understood as integrated, not independent; 2) People should strive for the mean with respect to each virtue, that more of a virtue is not always better; and 3) There is a master virtue: practical wisdom, essential for orchestrating the other virtues into an effective and happy life. Schwartz and Sharpe (2006, p. 381) argue that the Aristotelian virtue of practical wisdom must come into play as a master virtue in order to solve problems of specificity, of relevance, and of conflict, which can always arise whenever character strengths are translated into behaviour in real life situations.

In articulating these important differences within the literature, our own reflections emerge regarding PP and its approach to the notion of virtues in fostering a good life and wellbeing. From a clinical perspective, we question the complexity of working with a large but finite number of strengths to be fostered in the context of client distress. We also wonder about the possible implications of overuse and underuse of these strengths and their relationship to client overall

\footnotetext{
${ }^{8}$ Virtue seen as the "mean or right middle" is different from the medium, because for each situation one must know how to adjust its position between the extremes. In some situations you have to be more fearful, whereas in others you have to be more fearless. For example, if an unknown person insults you on the sidewalk, it is better to continue on your way with a fear of an altercation, because choosing to respond with a fight would be considered silly and intrepid. But if someone physically threatens a loved one, it would be courageous and (normal) to get up and dare to defend that person, even if there are violent blows, because freezing in fear is not appropriate in this particular context. The brave human being always chooses the appropriate response: sometimes he (or she) is fearful, sometimes he (or she) is fearless. "The virtuous act" could be translated as "the appropriate act."
} 
wellbeing. Furthermore, we question the concept of the person and development of strengths. These reflections are detailed below.

\subsection{Reflection one: The finite number of identified virtues}

Some studies have cast doubt on the existence of six higher order virtues, suggesting that the 24 character strengths as proposed by Peterson and Seligman (2004) may be better represented by a four, three or even two-factor model (cf. Macdonald, Bore, \& Munro, 2008; Brdar \& Kashdan, 2010; McGrath, 2015; Martin-Krumm \& Tarquinio, 2011). Other authors also suggest that the socio-cultural dimension is lacking from the PP's strengths and virtues research (Martin-Krum \& Tarquinio, 2011). Furthermore, not only are virtues difficult to conceptualize, measuring these 24 strengths is also a complex task (Peterson \& Seligman, 2004). Given the ambiguity surrounding their conceptual grouping, one may wonder how it is possible to concretely foster all 24 of these strengths in each individual person. That is, psychotherapists may struggle with how to go about fostering the discovery (acquisition) of virtues and strengths in the context of extreme distress or severe mental illness. More importantly, because of the relative ease of operationalizing character strengths, this may divert valuable resources from actually measuring the cardinal virtues directly, which are thought to be relevant for moral education (cf. Laprée, 2000; 2013).

\subsection{Reflection two: The overuse or underuse of strengths}

This reflection refers to the development and practice of virtues and how or whether it is possible to achieve balance. For example, how can one balance being kind and genuine, being courageous and prudent, showing a sense of equity and a capacity to forgive, self-control and zest, or showing loyalty and open-mindedness at the same time? These questions can be viewed as personal ethical dilemmas which have been linked to the problem of overuse and underuse of strengths (Schwartz \& Sharpe, 2006). Both overuse as well as underuse of strengths can have a negative impact on individual wellbeing (Grant \& Schwartz, 2011). As previously mentioned, Schwartz and Sharpe (2006) have suggested that the VIA character strengths cannot be treated independently from one another, and should be cautioned from overuse. They also suggest that a "master" strength of practical wisdom is needed in order to effectively deploy one's optimal range of strengths. Finally, Fowers (2008) emphasizes the importance of developing all 24 strengths and the importance of balance among the range of virtues for "unity of character," as opposed to Peterson and Seligman's (2004) approach which focuses on cultivating signature character strengths.

\subsection{Reflection three: The definition of wellbeing}

Research findings have established significant positive correlations between VIA character strengths and wellbeing (Peterson \& Seligman, 2004). However, the challenge lies in the fact that the notion of wellbeing is not monolithic across all cultures. For example, Wong (2016a) has coined the term, the dialectics of wellbeing. Dialectics in the Merriam Webster Dictionary (2017) refers to the "dialectical tensions or opposition between two interacting forces or elements." Positive and negative emotions are opposites, but they are also intimately connected. In this sense, their relationship is not a static one but continues to evolve through the interplay of the two polarities (Lomas \& Ivtzan, 2016). Furthermore, wellbeing and ill-being are not two poles of a continuum, but are two separate dimensions of functioning (Keyes, 2007). For example, avoidance and approach are not two opposite poles of the same dimension, but may exist in 
parallel. To avoid or to approach is based on what is required under the circumstance. Optimal levels of adaptation and wellbeing can be achieved through the dialectical interplay between two coexisting adaptive systems (Wong, 2016b). Individuals use different approaches for coping, based on their personality and the situations they encounter.

\subsection{Reflection four: Embracing the wholeness of the person}

As mentioned in reflection 3, according to Positive Psychology 2.0 (Wong, 2011; 2015; 2016c), it is important to consider both sides of human nature; the luminous and the dark sides. This can also apply to the notion of virtues. Focusing only on virtues without recognizing the dark side can be analogous to focusing on nutrition without considering the possible contamination by bacteria and toxins. Examples of dialectics of virtues include courage vs. fear, temperance vs. greed, transcendence vs. selfishness, and humanity vs. domination. Therefore, PP 2.0 argues that it is not possible to properly study virtues without taking into account the inevitable vices that define the need for virtues. Similarly, Fowers (2008) also argues that "Understanding good character is dependent on contrasting it with less noble character types to highlight the key features of virtue" (p. 630).

\subsection{Reflection five: Fostering the development of strengths}

At the website www.viacharacter.org, a list of two to four interesting and concrete activities are provided to assist in improving each of the 24 character strengths. Despite their relevance, it can be time consuming or challenging for clinicians to select the best activity among a list of over 75 possible ones. Psychotherapists and clinicians may struggle with sifting through an array of choices, and experience doubt, if not some stress, about this. In this sense, clinicians may benefit from a more heuristic way of guiding the development of their clients' character strengths.

In sum, Schwartz and Sharpe's (2006) critique of PP's perspective on character strengths and virtues, along with the five reflections above, suggest the relevance of proposing an alternative theoretical framework for understanding virtues and character strengths. Indeed, one may wonder what constitutes a "master" strength (or superordinate one) of practical wisdom. How do we find a balance between character strengths that should not be treated independently? One may have to imagine other ways of knowing. Just like images can communicate to us in ways that words fail, the ability to create an imagined world helps us find our unique position in a world of reality (Rautenberg, 2010). In seeking answers to the above questions, we suggest that a more heuristic framework could assist us in making sense of the complexity inherent to the notion of virtues and their associated characters strengths. Specifically, we suggest that Durand's theory of imaginary can serve to provide a model that will help to foster a good life, according to Aristotle (trans. 2000). Durand's ASI is a culturally sensitive framework that can embrace multiple factors at a higher symbolic level, as well as the notion of dialectics (e.g., virtues vs. vices), through the use of a third path (i.e., the systemic mythical category) in what we suggest is a more practical and simple way.

As Schwartz and Sharpe (2006) suggest, "It takes imagination and perception to translate virtue into action in any situation" (p. 381). Aligned with the appreciation of a good life, according to Aristotle, Somerville (2006) has proposed the close relationship between ethics, imagination, and the symbolic capacity of human beings. This leads us to a different yet complementary view of human beings, proposed by Durand's (1960) Anthropological Structures of the Imaginary (ASI). In this view, human beings are seen as homo symbolicus (i.e., human beings 
with a symbolic capacity). Within this culturally sensitive framework ${ }^{9}$ (Wunenburger, 2013), the various elements of personality (virtues, strengths) are embedded in a more broad and global understanding of humankind (Durand, 1960).

\section{A brief overview of Durand's theory of Anthropological Structures of the Imaginary}

Philosopher and cultural anthropologist Gilbert Durand (1921-2012) developed his theory of Anthropological Structures of the Imaginary (ASI) as an attempt to encompass what it is to be completely "human." His theory addressed issues of existence, structuring and imaginary. In his view, homo sapiens inhabit this world not by means of a predetermined nature from basic instincts, but by symbolic structures that create meaning. Structures are brought about by the individuals' ability to interpret and make sense of their experiences. This human capacity to interpret, homo symbolicus, leads to the creation of symbolic structures which guide human action. The structuring of meaning is created and transformed through interaction with one's environment, and thus culture is considered a starting instinct in life, transmitted through ancestral lineage. The imaginary refers to the repertory of items or images that define for an individual and their collective what is possible to imagine, or make sense of. In this sense, human beings are seen as acting through a symbolic mode or (innate) symbolic structures of the imaginary rather than acting on instincts. One can see these structures of the imaginary as referring to one's worldview.

Gilbert Durand's understanding of human action, guided by the Anthropological Structures of the Imaginary, has been inspired by many domains: literature, arts, music, philosophical and religious beliefs, mythologies, esotericism, schools of humanities, mainstream civilization trends and the hermeneutics of applied sciences. According to Durand (1960), there are, at the origin of human cultures, reservoirs of images and symbols which continue to shape our ways of thinking, living and dreaming. The imaginary is not just the concern of a rational approach, but is part of the whole human living constitution (Wunenburger, 2013). To realize his vision of the person, Durand $^{10}$ (1960) argues that these images and archetypal patterns, common to anyone, deploy in an "anthropological trajectory," defined as a "ceaseless exchange taking place on the level of the imaginary between subject assimilatory drives and objective pressures, emanating from the

\footnotetext{
${ }^{9}$ Kristjánsson (2010) has pointed out that proponents of positive psychology have been "accused of hustling a disguised ideology of conservative political individualism. The accusation is that positive psychology is all about selffulfillment qua personal happiness, and although it does mention social factors ('positive institution'), those are effectively relegated to being a side issue " (p. 298-299). However, Durand's theory of SAI is considered a culturally sensitive framework that takes into account Western and Eastern worldviews (Durand-Sun, 2013).

${ }^{10}$ Indeed, in his seminal work The Anthropological Structures of the Imaginary (ASI), Gilbert Durand (1960) considers the human being as a homo symbolicus, and the whole symbolic world of the latter constitutes the capability of his imaginary. Note that, as opposed to one individual's particular imagination, the term imaginary (from the French noun "imaginaire," and not its adjective equivalent), refers to the general and collective human ability to imagine, which Durand (1979) calls "the whole human universe" (p. 23). Durand (1960; 1992) hereby reinforces the affirmation of his master Gaston Bachelard (1948), with a first axiom: "the images that are raw psychic forces are stronger than ideas, stronger than the actual experiences" (p.20, our translation). Therefore, these "images [are] loaded with ambivalent emotions and symbolic correlates, organized into coherent networks which feed all symbolic expressions. The result is that human rationality is always acquired second." (Wunenburger, 2013, p. 9, our translation). A second axiom in Durand's ASI focuses on temporality - under both the Eastern and Western conceptions of time - of the imaginary, which comes in the form of functions designed primarily to help tame the passing of time and deal with the existential anguish of death: "Finally, the imaginary is basically a temporal psychic activity, that is to say, both subject to time and able to challenge the destructive time exposing us to death" (Wunenburger 2013, p. 9, our translation).
} 
cosmic and social milieu" (Durand, 1999, p. 41). There is a constant exchange between culture and the individuals within a society. Culture plays a significant role in shaping worldview and influencing values.

\subsection{Durand's classification of structures of the imaginary}

Durand (1960) divides mental images and visual narratives of all cultures into two large polarities - the "diurnal" and the "nocturnal" - which are in opposition. These polarities are based on opposing worldviews or structures of the imaginary. However, to ensure the continual existence and balance of the regimes, a "synthetic system" is needed to allow the two opposing regimes - the heroic and the mystical - to co-exist and to maintain the balance between them (Durand, 1999). Diagram A (page 21) offers an abridged version of Durand's classification of the Anthropological Structures of the Imaginary.

The visual representations in Diagram A demonstrate the main differences between the three structures. A bright yellow circle is used to represent the heroic structure, as it echoes the diurnal polarity, the verbal schema "to distinguish," and also resonates the energy of productivity and constant tension in life. A darker (midnight blue) circle is used to represent the mystical structure, as it echoes the nocturnal polarity, the verbal schema "to confound" and at the same time resonates with the energy of solidarity, harmony and a peaceful life.

Finally, in the middle, a swirling circle ${ }^{11}$ with both the bright and the dark colours is used to represent the systemic structure as it echoes the verbal schema "to link," and also resonates with energy of regulation. Note that in the systemic structure, there is no "blending" of the two polarities (which would best be represented by a green circle, blending yellow and midnight blue); instead, the swirl illustrates the harmonious co-existence of opposites. Another meaningful symbol of systemic structure is the yin-yang symbol. This brief introduction to Durand's ASI can be further described by presenting, one by one, these three main mythical categories (heroic, mystical and synthetic) in more detail.

The heroic structure: The diurnal regime, or the schizomorphic or heroic and purist structure, is the daytime image characterized by the verbal schema "to distinguish" and the dominant postural position of "getting up or standing, ascending," or the upward rising thrust (Bellehumeur et al., 2013). The heroic structure, in its postural reflexive gesture, predisposes to stand, to ascend, to separate (or distinguish or clarify) what is good and elevate us from what is bad or evil and what makes us fall, to purify, to struggle to victory (Laprée, 2000). It carries the notion that heroes have to stand and fight and overcome any challenge they face (Xiberras, 2002). This heroic structure echoes St-Arnaud's (1989) axis of productivity (Bellehumeur \& Carignan, in press). In sum, there is always a sense or an energy of constant tension, not peace, within the heroic structure.

The mystical structure, arising from the nocturnal polarity. Durand uses the word mystical to allude to this mystery of ourselves. However, to avoid confusion of language, we prefer to speak of intimacy (or interiority) for this structuring. Within the mystical structure, the verbal schema is "to confound," whose reflexive gesture is digestive or absorbing, which tends to receive within oneself (Durand, 1960). This can also be understood as "to merge," so that two entities are now

\footnotetext{
${ }^{11}$ Although the visual presentation of systemic structure indicates a cyclical motion in a one-way direction of going down (spiral downward), it is important to keep in mind that this motion, according to Durand's image of yin-yang, has truly the motion of going back and forth (back to the original, a two-way motion). For Durand, the reflex can trace back to culture, and the culture to the reflex. His theory can be applied from either way, as this is about regulation; things can go in either direction, a two-way movement, interrelationship, or going back to the original.
} 
indistinguishable. In this state of fusion, everything is friendly, gentle, peaceful, warm, harmonious and internalized. "[W]ords are softened by figures of speech, such as the euphemism... 'the fall is slowed to a descent' (Xiberras, 2002, p. 66)..." (Laprée, 2013, p. 156). This is sort of a "solidarity building" energy (St-Arnaud, 1989), which echoes the analogy and similarity principles that are found in Durand's mystical structure. Indeed, it is important that each person feel good, that he finds his place within the relationship, while giving the other the same psychological space. Each person is seen as trying to create for the other an atmosphere of confidence and security.

\subsection{The systemic structure: An energy of "regulation"}

Durand also identified a third structure called "synthetic" (later re-named "systemic"), arising from what he called in later writings the "crepuscular" regime occurring between the nocturnal and diurnal polarities. The crepuscular regime is not a polarity, as are the nocturnal and diurnal regimes, but refers "rather to an imaginary place of connection between these first two [heroic and mystical structures]" (Laprée, 2013, p. 157). This structure refers to the third path, where both the diurnal and nocturnal regimes co-exist harmoniously because the principle of causality exists in this system. The systemic structure's verbal schema is "to link," and its reflexive gesture is oscillating, rhythmic, or cyclical, tending to synthesize or hold opposites together in harmony without any will of exclusion. This is like the linking of opposite principles in the Chinese philosophy of yin-yang (Wong, 2016c). While the synthetic structure embraces paradox, Durand believes that personality disorders and social unrest can result from the disbalance of the heroic or mystical regimes being off-balance (Bellehumeur et al., 2013; Laprée, 2000). According to Durand-Sun (2013), the antithesis of Eastern and Western values can co-exist. The effects of these external and intrapsychic influences on a human being's wellbeing can be revealed through their mythical categories of the imaginary. If one leans too much on the heroic side, the sense of wellbeing may be associated with too much stress; if one leans too much on the mystical side, there may be a lack of personal goal and healthy challenge in that person's makeup.

\section{Applications of Durand's ASI to PP's conceptualization of character strengths and virtues}

In what follows, we will apply Durand's ASI to the study of character strengths and virtues. But first, two points must be made. First, it is important to note that establishing the links between the theoretical constructs of strengths and virtues and ASI is both theoretically and epistemologically challenging. Both of these theories rely on Greek classical philosophers that have complementary views of human nature. Durand's theory of the imaginary tends to be closer to Plato (Mattei, 1993; Wunenburger, 1997; 2013) and the theory of virtues is closer to Aristotle's philosophy (Peterson \& Seligman, 2004). However, given the empirical evidence of Durand's theory, along with the five reflections above, the relation between mythical categories and virtues and strengths seems logical and reasonable to propose.

On a more practical note, in our attempt to classify strengths, we have noticed that some are more easily classified than others. In order to improve the scientific rigor, from a methodologically perspective, the three co-authors (one from Eastern Chinese cultural background, one from French Canadian and one from English Canadian background) have classified independently these 24 strengths. Consensus was reached through inter-rater discussion. Inter-rater agreement prior to discussion ranged between 70 and $80 \%$. 
Diagram B attempts to illustrate an overall distribution of the six main virtues into two distinct polarities of the imaginary. Diagram $C$ is more specific in categorizing the 24 strengths. We remain tentative in our approach and aware of the need for future research.

Diagram B. ASI as a heuristic classification of virtues

\begin{tabular}{ll}
\hline Diurnal Polarity & Nocturnal Polarity \\
\hline Wisdom and knowledge & Humanity \\
Courage & Temperance \\
Justice & Transcendance (Systemic) \\
\hline
\end{tabular}

Diagram C. Mythical structures as a heuristic classification of strengths

\begin{tabular}{|c|c|c|}
\hline $\begin{array}{l}\text { Heroic Structure } \\
\text { (Diurnal regime) }\end{array}$ & $\begin{array}{l}\text { Systemic Structure } \\
\text { ("Crepuscular " regime) }\end{array}$ & $\begin{array}{l}\text { Mystical Structure } \\
\text { (Noctural regime) }\end{array}$ \\
\hline Creativity/Ingenuity & Curiosity & Love/Intimacy \\
\hline Love of learning & Perspective & Kindness \\
\hline Bravery & Leadership & Citizenship/teamwork \\
\hline Industry/perseverance & Regulation/self-control & Modesty/humility \\
\hline Zest & Hope & Prudence \\
\hline Judgment/critical thinking & Spirituality & Gratitude \\
\hline Fairness & Social intelligence & $\begin{array}{l}\text { Awe/appreciation of beauty } \\
\text { and excellence }\end{array}$ \\
\hline Honesty/authenticy/integrity & Forgiveness/mercy & Humor/playfulness \\
\hline
\end{tabular}

What follows is a case study to further illustrate the relevance of Durand's theory of the imaginary to the study of virtues and strengths for conceptualization and treatment planning.

\section{Case study: Marcella}

Marcella is a 29-year-old married female with no children. She and her five siblings were raised in Argentina by her single mother and maternal grandparents. While she states she had a good relationship with her family, she also states her mother struggled with depression throughout her childhood, and, as a consequence, was often emotionally unavailable. Growing up, Marcella describes frequently feeling inadequate in relation to others. She explains her disadvantaged childhood made her have to "work harder than others to prove herself" and she felt as though she was never given the opportunity to achieve her true potential. At the age of 18, Marcella left Argentina to travel the world in "pursuit of opportunity." She explains that it was in India where her life changed and she discovered purpose and meaning in life through engaging in their meditative practices, mentored by a gifted spiritual leader who had a major influence on her spiritual life. This allowed Marcella to experience a deep spiritual connection and newfound gratitude in her own life. After two years of studying meditation in India, she came to Canada to study psychology in order to help others discover and find themselves.

She is currently enrolled in a demanding Canadian graduate-level program to become a clinical psychologist. Marcella describes herself as extremely competent in her work as a psychotherapist, given her life experience, and reports having a special ability to be perceptive of others, appreciate them and be sensitive to their needs. Lately, however, she reports struggling with feelings of disillusionment in regards to her program of study and its reductionist view of healing. She explains experiencing frustration at the lack of competence exhibited by her peers 
and resentful of her clinical supervisor, who fails to recognize the importance of her exceptional knowledge and skills regarding meditation for healing and her above-average capabilities. This has led her to use techniques she learned in her travels, regardless of the fact that they had not been approved by her clinical supervisor. Because of this, her supervisor questioned her ethical awareness, which resulted in tensions between them. Marcella reports that her perceived lack of freedom in her practice and lack of trust from her supervisor led her to attempt to conceal her use of spiritual practices with clients, leading to the eventual removal of her clients. In consequence, she states feeling excluded, insecure and worried about how she is professionally perceived in the program.

\subsection{Brief analysis of the case study}

Marcella presents with anxiety related to her current struggles in her graduate program. Marcella's case could be examined from various clinical perspectives. For example, her sufferings could be seen through the lens of attachment (Bowlby, 1988), related to her psychologically absent mother. She could also be seen as experiencing a sense of isolation due to her move to Canada and the cultural differences between individualistic and collective cultures, resulting in acculturation stress (Berry, 2005, p. 708). A third existential lens could perceive a possible conflict of values between the mainstream approach (e.g., clinical psychology) and her value of spiritual orientation. In other words, Marcella could be experiencing a lack of meaning in her life, expressed as a lack of meaningful relationships and meaningful engagement. The proposed treatment could be to focus on the human capacity for imagination and meaning-making in order to create an alternative world that incorporates her spiritual world with the Western individualistic world.

All of these clinical avenues could be relevant for treatment. Furthermore, conceptualizing Marcella's case solely from the lens of virtues may not sufficiently take into account the complexity of her situation. However, to better illustrate our previous points on the conceptualization of virtues, let us turn to the notions of virtues and character strengths.

First, from Seligman's model of strengths, Marcella demonstrates strengths in the area of awe and gratitude, mostly related to her past spiritual experiences in India, which have shaped her expectations of current academic experiences. From this perspective, strengths are seen as independent, and consequently, Marcella would be encouraged to focus on these strengths individually to increase her wellbeing by applying her strengths in gratitude and awe in other domains, for example, by transferring her awe and gratitude to the academic expertise and knowledge that is offered to her by her professors, clients and colleagues.

Second, from an Aristotelian perspective, the idea of practical wisdom would require strengths to be viewed through the lens of practical wisdom, which requires appropriate dosage of virtues and strengths to balance their integration in such a way that one would strive to the mean with respect to each virtue in order to achieve a better and happier life. From this perspective, Marcella would demonstrate strengths in awe and gratitude, but deficiencies in strengths related to judgment and honesty (towards her clinical supervision). Despite the fact that Marcella strongly believes in her exceptional skills with regards to spirituality, a perceived lack of authenticity may also be interpreted as her desire to remain true to her own beliefs and values. However, within the context of her training, Marcella's attempt to conceal her practices with clients has resulted in the removal of her clients and in tensions with her supervisor (who was ethically responsible for her clients). Therefore, despite Marcella's good intentions of wanting to help her clients to the best of her abilities, she could be seen as possibly benefitting from a focus on increasing her humanity (mostly social intelligence) and transcendence (such as 
experiencing more hope in her clinical supervisor's abilities to train her well) to help in recognizing all people as members of the human family, despite their difference in opinions and professional preferences. Finally, to avoid any further conflict with her clinical supervisor, Marcella could have benefitted from discussing her perspective with her supervisor sooner, in a humble way, to articulate her beliefs with regards to why spiritual interventions and meditation are so important for her at this stage of learning. Given that cultural competency is required both in psychotherapy and in supervision, one could expect that her clinical supervisor could be open to hearing about this. If not, it would take courage from Marcella to do so. Her overemphasis on awe and gratitude is seemingly out of balance with her judgment and honesty. Practical wisdom would allow her to do the right thing at the right moment. In Marcella's situation, it could be seen as the need to balance her developed awe and gratitude from previous positive experiences, to leave room for the requirements of her current situation, which require her to exercise judgment and express her awe and gratitude in a more honest way. This could also allow her to express her legitimate experience of vulnerability as a trainee. For example, Marcella could share her impression of not feeling fully validated by her clinical supervisor for her self-perceived gifts of above-average spiritual awareness and skills.

Revisiting Diagram C, inflated awe and gratitude, combined with deficiencies in judgment and honesty suggest an imbalance from Durand's perspective. There is an exaggeration of the mystical structure undermining the heroic structure. Therefore, Marcella may also benefit from recognizing her need to develop the virtue of wisdom and knowledge, her critical judgment (along with a stronger motivation to learn more about counseling and psychotherapy ethics in working with clients). Also, Diagram C, balancing these two mythical regimes into the systemic structure, could foster a more integrated and holistic awareness of her of spirituality, accompanied by a deeper functioning with regards to social intelligence.

\section{Conclusion}

Despite its remarkable contribution, which has captured the interest of a growing number of researchers, the field of Positive Psychology's concepts of strengths and virtues is not without its critics (Schwartz \& Sharpe, 2006). As Fowers (2008, p. 641) and Kristjánsson (2010, p. 307) have recognized, despite some Aristotelian misgivings identified in Peterson and Seligman's (2004) approach to virtue, these two later authors of the VIA both acknowledged that they are still in development: "yet-to-be-articulated good theory that make sense of the classification entries, individually and collectively" (p. 9). In this article, we have attempted to apply a theoretical understanding of Durand's ASI, seen for a more integrated and holistic vision of a human being and for a more nuanced approach to understanding Positive Psychology's concepts of strengths and virtues. We suggest that Durand's theory of ASI could be proposed as a complementary theoretical framework, taking into account the complexity of studying both virtues and character strengths.

Earlier in this article, we briefly referred to the contributions of the "second wave" of Positive Psychology (PP 2.0) (Ivtzan, Lomas, Hefferon, \& Worth, 2015; Wong, 2011; 2015) which is an umbrella under which there is the inclusion of many defining themes. It is most interesting to note that Durand's theory of the imaginary has various epistemological similarities with PP 2.0. We proposed that these similarities allow for a matching of Wong's (2015) defining themes of PP 2.0 and Durand's theory of the imaginary. Diagram D summarizes the main similarities between the basic tenets of PP 2.0 and Durand's theory of the imaginary. 


\section{Diagram D. Similarities between PP 2.0 and Durand's Theory of the Imaginary}

\footnotetext{
Positive Psychology 2.0 (Wong, 2011; 2016a, b, c)

Dialectical view (embracing both light and dark sides of human nature); Yin-Yang symbol.

Embracing and transforming the dark side of human existence echoes the willingness to confront our own mortality and make the best use of our limited time on earth.
}

Capacity to consider unpleasant and undesirable territories such as suffering, terminal illness and death, as well as the positive side of life.

Cultivating humanistic or global virtues not only at the individual level but also at the societal level; balance of yin and yang as a dynamic process; achieving the right balance depends on both internal and external conditions.

Pathways to wellbeing may be shaped by cultural differences.

Welcoming of various ways of knowing (quantitative research grounded in the epistemology of positivism; qualitative research and knowledge from humanities such as philosophy, literature and religion).

Considering the optimal wellbeing of individuals and organizations and the good life from a perspective that transcends traditional polarities (e.g., happinesssadness, vice-virtue) through adopting a transcendent lens that perceives over and above a commonly adopted either-or binary continuum.

\section{Durand's (1960) Theory of the Imaginary}

Yin-Yang symbol echoes the systemic (synthetic) mythical category.

The imaginary as an answer to our existential fear of death and time flying by.

Both polarities such as life and death, suffering and happiness may co-exist.

The imaginary is dynamic and Durand's theory relies on both internal and external elements, which are part of the anthropological trajectory.

Culturally sensitive framework, embracing Western and Eastern worldviews.

Embracing human reality as a whole, taking into account various ways of knowing from multiple disciplines.

Optimal wellbeing and optimal mental health echo the systemic mythical category, where opposites co-exist (Laprée, 2000; Durand, 1979).

In sum, applying Durand's theory in conceptualizing Marcella's use of her strengths suggests other possible ways for psychotherapists to approach and support Marcella's efforts in moving forward. Although there may be other patterns or conceptualizations that could be identified as relevant for Marcella to consider in her personal and professional development, we argue that a balanced approach to integrating positive aspects of heroic structure and positive aspects of nocturnal regime (Durand's mystical and systemic structures) would greatly benefit Marcella and ease the identification of the various development areas she is faced with. Within the systemic structure (where, according to Durand), we find optimal wellbeing, Marcella could discover strengths such as perspective and social intelligence, as mentioned above, that would be greatly beneficial for her to move forward in her current challenges.

The three original pillars of Positive Psychology identified by Seligman (2011) were positive subjective experience, positive individual characteristics (virtues and strengths) and positive institutions and communities. To date, Positive Psychology has produced much research on the first two areas but there remains a lack of research in the third pillar (Gable \& Haidt, 2011). Therefore, the proposition of applying Durand's theory to notions such as virtues and strengths does not only serve the purpose of this theoretical concern per se. It echoes one main recommendation made by top researchers in the field of Positive Psychology who have previously shared concerns about the lack of research on integrating a more socially and 
culturally sensitive view of human nature (Gable \& Haidt, 2011). According to them, the field of Positive Psychology needs to create links with a "positive sociology" and a "positive anthropology." Therefore, in this article, we have briefly demonstrated how Durand's Anthropological Structures of the Imaginary can be seen as a valuable framework which takes into consideration social and cultures dimensions of human nature.

As more research is needed to better include various social and cultural influences to the notions of virtues and strengths, we agree with Schwartz and Sharpe's (2006, p. 386) claim that practical wisdom requires other strengths that are not on the Peterson and Seligman list. For future research, it would be interesting to see how other religious traditions, such as the Buddhism tradition and its emphasis on the virtue of detachment may influence the understanding of Western classification of virtues and strengths. Moreover, future research could focus on the role of strengths, such as flexibility and adaptability, which seem underrepresented in the Peterson and Seligman list. Given the fact that cognitive rigidity has been found to lead to mental illness (depression and anxiety), flexibility is necessary in managing wellness in the complexity of the life context. Finally, we agree again with Schwartz and Sharpe's (2006, p. 386) claim about how "practical wisdom requires other strengths that are not on the Peterson and Seligman list [such as ] ... imagination."

\section{Authors}

Christian R. Bellehumeur

Saint Paul University

cbellehumeur@ustpaul.ca

Cynthia Bilodeau

Saint Paul University

Winnie Yeung

Saint Paul University

Publishing Timeline

Received 29 June 2017

Accepted 14 November 2017

Published 12 December 2017

\section{References}

Aristotle. (trans. 2000). The Nicomachean ethics. (R. Crisp, Trans.) Cambridge, UK: Cambridge University Press.

Bachelard, G. (1948). La Terre et les rêveries du repos. Paris, France: José Corti.

Bellehumeur, C. R., Lavoie, L.-C., Malette, J., Laprée, R., \& Guindon, M. (2013). An empirical study of young French Quebecers' imagination using the Archetypal Test with Nine Elements: Exploring the links between interpersonal style and socio-economic status. International Journal of Interdisciplinary Cultural Studies, 7(3), 11-25. https://doi.org/10.18848/2327-008X/CGP/v07i03/53167

Bellehumeur, C.R., Carignan, L.-M. (in press). Meaning-making in the identity-intimacy paradox in couple relationships: A perspective based on Gilbert Durand's Anthropological Structures of the imaginary. In L. Armstrong (Ed.). Existential Elements of the Family. Leuven, Belgium, Peeters.

Berry, J. (2005). Acculturation: Living successfully in two cultures. International Journal of Intercultural Relations, 29(6), 697-712. https://doi.org/10.1016/j.ijintrel.2005.07.013

Bowlby, J. (1988). A secure base: Parent-child attachment and healthy human development. New York, NY: Basic Books. 
Brdar, B. \& Kashdan, T. (2010). Character strengths and well-being in Croatia: An empirical investigation of structure and correlates. Journal of Research in Personality, 44(1), 151-154. https://doi.org/10.1016/j.jpp.2009.12.001

Durand, G. (1960 [1992]). Les structures anthropologiques de l'imaginaire: Introduction à l'archétypologie générale. Paris, France: Dunod.

Durand, G. (1979). Figures mythiques et visage de l'auvre: De la mythocritique à la mythanalyse. Paris, France: Berg International.

Durand, G. (1999). The anthropological structures of the imaginary. Brisbane : Boombana Publications.

Durand-Sun, C. (2013). Gilbert Durand et l'imaginaire de l'Orient. In R. Laprée \& C. R. Bellehumeur (Eds.), L'imaginaire durandien: Enracinements et envols en terre d'Amérique (pp. 21-38). Québec, Canada: Presses de l'Université Laval.

Fowers, B. J. (2008). From continence to virtue: Recovering goodness, character unity, and character types for positive psychology. Theory \& Psychology, 18(5), 629-653. https://doi.org/10.1177/0959354308093399

Gable, S. L. \& Haidt, J. (2011). Qu'est-ce que la psychologie positive (et pourquoi)? In C. Martin-Krumm \& C. Tarquinio (Eds.), Traité de psychologie positive (pp. 29-40). Brussels, Belgium: De Boeck Supérieur, collection: Ouvertures Psychologiques.

Govindji, R., \& Linley, P. A. (2007). Strengths use, self-concordance and well-being: Implications for strengths coaching and coaching psychologists. International Coaching Psychology Review, 2, 143-153.

Grant, A. M., \& Schwartz, B. (2011). Too much of a good thing: The challenge and opportunity of the inverted U. Perspectives on Psychological Science, 6, 61-76. https://doi.org/10.1177/1745691610393523

Ivtzan, I., Lomas, T., Hefferon, K., \& Worth, P. (2015). Second wave positive psychology: Embracing the dark side of life. London, UK: Routledge.

Kaczor, C. (2015). The gospel of happiness: Rediscover your faith through spiritual practice and positive psychology. New York, NY: The Doubleday Religious Publishing Group.

Keyes, C. L. M. (2007). Promoting and protecting mental health as flourishing: A complementary strategy for improving national mental health. American Psychologist, 62(2), 95-108. https://doi.org/10.1037/0003-066X.62.2.95

Kristjánsson, K. (2010). Positive psychology, happiness, and virtue: The troublesome conceptual issues. Review of General Psychology, 14, 296-310. https://doi.org/10.1037/a0020781

Laprée, R. (2000). La psychagogie des valeurs. Symbolique et imaginaire en éducation, Montréal, Canada: Éditions Logiques.

Laprée, R. (2013). La dynamique de groupe et les structures anthropologiques de l'imaginaire. In R. Laprée \& C. R. Bellehumeur (Eds.), L'imaginaire durandien. Enracinements et envols en Terre d'Amérique (p. 149-165). Québec, Canada: Presses de l’Université Laval.

Lomas, T., \& Ivtzan, I. (2016). Second wave positive psychology: Exploring the positive-negative dialectics of wellbeing. Journal of Happiness Studies 17, 1753-1768. https://doi.org/10.1007/s10902-0159668-y

Macdonald, C., Bore M., \& Munro, D. (2008). Values in action scale and the Big 5: An empirical indication of structure. Journal of Research in Personality, 42, 787-799. https://doi.org/10.1016/j.jrp.2007.10.003

Martin-Krumm. C., \& Tarquinio, C. (2011). Traité de psychologie positive (pp. 29-40). Brussels, Belgium: De Boeck Supérieur, collection: Ouvertures Psychologiques.

Mattei, J.-F. (1993). Le mythe et l'image chez Platon. In B. Curatolo \& J.- J. Wunenburger (Eds.). L'imaginaire des philosophes. Paris, France : L'Harmattan.

McGrath, R. E. (2015). Integrating psychological and cultural perspectives on virtue: The hierarchical structure of character strengths. Journal of Positive Psychology, 10(5), 407-424. https://doi.org/10.1080/17439760.2014.994222

Merriam Webster Dictionary. (2017). https://www.merriam-webster.com

Park, N., Peterson, C., \& Seligman, M. E. P. (2004). Strengths of character and well-being. Journal of Social and Clinical Psychology, 23, 603-619. https://doi.org/10.1521/jscp.23.5.603.50748

Peterson, C., \& Seligman, M. E. P. (2004). Character strengths and virtues: A handbook and classification. New York, NY: Oxford University Press. 
Rautenberg, M. (2010). Stereotypes and emblems in construction of social imagination. Outline-Critical Practice Studies, 2, 126-137. https://ojs.statsbiblioteket.dk/index.php/outlines/article/viewFile/2687/3348

Somerville, M. (2006). The ethical imagination: Journeys of the human spirit. Toronto, Canada: House of Anansi Press.

St-Arnaud, Y. (1989). Les petits groupes. Participation et communication. Montréal, Canada : Les Presses de l'Université de Montréal, Les Éditions du CIM.

Seligman, M. E. P. (2011). La fabrique du Bonheur: Vivre les bienfaits de la psychologie positive au quotidien. Paris, France: InterEditions.

Seligman M. E. P., \& Csikszentmihalyi, M. (2000). Positive psychology. An introduction. The American Psychologist, 55, 5-14. https://doi.org/10.1037/0003-066X.55.1.5

Schwartz, B., \& Sharpe, K. E. (2006). Practical wisdom: Aristotle meets positive psychology. Journal of Happiness Studies, 7, 377-395. https://doi.org/10.1007/s10902-005-3651-y

Wong, P. T. P. (2011). Positive psychology 2.0: Towards a balanced interactive model of the good life. Canadian Psychology, 52(2), 69-81. https://doi.org/10.1037/a0022511

Wong, P. T. P. (2015). What is second wave positive psychology and why is it necessary? http://www.drpaulwong.com/what-is-second-wave-positive-psychology-and-why-is-it-necessary/

Wong, P. T. P. (2016a). Self-transcendence: A paradoxical way to become your best. International Journal of Existential Psychology \& Psychotherapy. 6(1), 1-9.

Wong, P. T. P. (2016b). The good life through polarity and transcendence (Part 1). Virtue, happiness, and the meaning of life. https://thevirtueblog.com/2016/10/18/the-good-life-through-polarity-andtranscendence-part-1/

Wong, P. T. P. (2016c). The good life through polarity and transcendence (Part 2). Virtue, happiness, and the meaning of life. https://thevirtueblog.com/2016/10/19/the-good-life-through-polarity-andtranscendence-part-2/

Wong, P. T. P. (2016d). Acceptance, transcendence, and yin-yang dialectics: The three basic tenets of second wave positive psychology. Positive Living Newsletter. www.drpaulwong.com/inpmpresidents-report-november-2016

Wunenburger, J. J. (1997). Philosophie des images. Paris, France : PUF.

Wunenburger, J.-J. (2013). L'anthropologie de l'imaginaire selon Gilbert Durand. Contextes, options, enjeux. In R. Laprée \& C. R. Bellehumeur (Eds.). L'imaginaire durandien: Enracinements et envols en Terre d'Amérique. Québec, Canada: Presses de l'Université Laval.

Xiberras, M. (2002). La pratique de l'imaginaire. Lecture de Gilbert Durand, Québec, Canada: Les Presses de l'Université Laval.

Zagano, P., \& Gillespie, C. K. (2006). Ignatian spirituality and Positive Psychology. The Way, 45(4), 41-58.

http://dictionary.cambridge.org/dictionary/english/virtue

http://www.viacharacter.org/viainstitute/classification.aspx 
Appendix 1. VIA classification of character strengths (Peterson \& Seligman, 2004)

1. Wisdom and knowledge - cognitive strengths that entail the acquisition and use of knowledge

- Creativity: Thinking of novel and productive ways to do things; includes artistic achievement but is not limited to it

- Curiosity: Taking an interest in all of ongoing experience; finding all subjects and topics fascinating; exploring and discovering

- Judgment/critical thinking: Thinking things through and examining them from all sides; not jumping to conclusions; being able to change one's mind in light of evidence; weighing all evidence fairly

- Love of learning: Mastering new skills, topics, and bodies of knowledge, whether on one's own or formally. Obviously related to the strength of curiosity but goes beyond it to describe the tendency to add systematically to what one knows

- Perspective: Being able to provide wise counsel to others; having ways of looking at the world that make sense to the self and to other people

2. Courage - emotional strengths that involve the exercise of will to accomplish goals in the face of opposition, external or internal

- Bravery: Not shrinking from threat, challenge, difficulty, or pain; speaking up for what is right even if there is opposition; acting on convictions even if unpopular; includes physical bravery but is not limited to it

- Industry/perseverance: Finishing what one starts; persisting in a course of action in spite of obstacles; "getting it out the door;" taking pleasure in completing tasks

- Authenticity: Speaking the truth but more broadly presenting oneself in a genuine way; being without pretense; taking responsibility for one's feelings and actions

- Zest: Approaching life with excitement and energy; not doing things halfway or halfheartedly; living life as an adventure; feeling alive and activated

\section{Humanity - interpersonal strengths that involve "tending" and befriending" others}

- Kindness: Doing favors and good deeds for others; helping them; taking care of them

- Love/intimacy: Valuing close relations with others, in particular those in which sharing and caring are reciprocated; being close to people

- Social intelligence: Being aware of the motives and feelings of other people and the self; knowing what to do to fit into different social situations; knowing what makes other people tick

\section{Justice - civic strengths that underlie healthy community life}

- Citizenship/teamwork: Working well as a member of a group or team; being loyal to the group; doing one's share

- Fairness: Treating all people the same according to notions of fairness and justice; not letting personal feelings bias decisions about others; giving everyone a fair chance

- Leadership: Encouraging a group of which one is a member to get things done and at the same time good relations within the group; organizing group activities and seeing that they happen 


\section{Temperance - strengths that protect against excess}

- Forgiveness/mercy: Forgiving those who have done wrong; giving people a second chance; not being vengeful

- Modesty/humility: Letting one's accomplishments speak for themselves; not seeking the spotlight; not regarding one's self as more special than one is

- Prudence: Being careful about one's choices; not taking undue risks; not saying or doing things that might later be regretted

- Self-control/self-regulation: Regulating what one feels and does; being disciplined; controlling one's appetites and emotions

\section{Transcendence - strengths that forge connections to the larger universe and provide meaning}

- Awe/appreciation of beauty and excellence: Noticing and appreciating beauty, excellence, and/or skilled performance in all domains of life, from nature to art to mathematics to science to everyday experience

- Gratitude: Being aware of and thankful for the good things that happen; taking time to express thanks

- Hope: Expecting the best in the future and working to achieve it; believing that a good future is something that can be brought about

- Playfulness: Liking to laugh and tease; bringing smiles to other people; seeing the light side; making (not necessarily telling) jokes

- Spirituality: Having coherent beliefs about the higher purpose and meaning of the universe; knowing where one fits within the larger scheme; having beliefs about the meaning of life that shape conduct and provide comfort 